\title{
MICROSCOPIA E USO DA CÂMERA DO CELULAR NAS AULAS DE BIOLOGIA: UM INSTRUMENTO DE REGISTRO DE ATIVIDADES
}

\author{
Amanda Vieira ${ }^{1}$ \\ Gabriela Fernandes ${ }^{2}$ \\ Julia Camargo Guimarães ${ }^{3}$ \\ Victória Gabriela Oliveira Souza ${ }^{4}$ \\ Elisa Celeste Dreux ${ }^{5}$
}

Resumo: O presente trabalho teve como objetivo a observação microscópica de estruturas reprodutoras vegetais ao microscópio monocular 116AL Coleman, objetiva 40x para ilustrar o ciclo de vida de grupos vegetais por alunos do Ensino Médio do Colégios Univap Aquarius, na Zona Oeste de São José dos Campos. O trabalho foi dividido em duas etapas: (a) a primeira etapa constituiu-se no estudo teórico dos grupos vegetais, ciclos reprodutivos e observação de estruturas reprodutoras de pteridófitas e angiospermas em aula de campo realizada na Praça Ulisses Guimarães, localizada no Jardim Aquarius; (b) a segunda etapa realizada no laboratório de Biologia do colégio, foram visualizadas ao microscópio óptico, soros, esporângios e esporos vegetais presentes em folhas de samambaias (Nephrolepis exaltata); e grãos de pólen de anteras coletadas de flores de "pata de vaca" (Bauhinia forticata). Complementando o resultado das atividades realizadas, os alunos utilizaram a câmera do celular (Iphone 5, câmera digital 8MP) acoplada a objetiva do microscópio registrando as estruturas observadas que foram compartilhadas nos grupos de estudo existentes nas redes sociais.

Palavras-chave: Microscópio; Soros; Grãos de pólen; Câmeras.

\footnotetext{
1 Alunos Colégio Univap Aquarius, Brasil. E-mail: amandavieirabykubrick@gmail.com.

2 Alunos Colégio Univap Aquarius, Brasil. E-mail: gabrielafernandes@gmail.com.

3 Alunos Colégio Univap Aquarius, Brasil. E-mail: ju.c.guimaraes@hotmail.com.

4 Alunos Colégio Univap Aquarius, Brasil. E-mail: victoriagabriela@gmail.com.

${ }^{5}$ Professora Colégio Univap Aquarius, Brasil. E-mail: ecdreux@ig.com.br.
} 